\title{
Concussion in rugby - an update
}

\author{
Ryan M N Kohler (MB ChB)
}

Medical Research Council/University of Cape Town Research Unit for Exercise Science and Sports Medicine, Department of Human Biology, University of Cape Town

\begin{abstract}
The decision to return a rugby player to the playing field after concussion has traditionally been controversial and indeed challenging for the team physician. However, recent advances at the First International Conference on Concussion in Sport, Vienna 2001 and the release of the South African Rugby Guidelines on the Management of Concussion 2002, have resulted in a comprehensive systematic approach to concussion being developed that would benefit the rugby player and assist with management decisions. The consensus is that the use of computerised neuropsychological tests forms the cornerstone of systematic concussion management. Objective cognitive function data can be obtained preseason and after concussion. Any deviation from baseline cognitive function after head injury can be detected. A player can return to play provided that there are no residual symptoms of concussion, cognitive function according to neuropsychological test data has returned to the pre-season baseline value and an exercise rehabilitation programme has been successfully completed. The aim of this article is to educate administrators, coaches, team medical personnel and rugby players about recent new developments in the management of concussion.
\end{abstract}

\section{Introduction}

Concussion is a trauma-induced change in mental state that may or may not involve loss of consciousness. ${ }^{1}$ The hallmarks of concussion include confusion and loss of memory (amnesia). ${ }^{1}$ This particular injury is common in rugby football. The incidence of concussion during a single rugby season at a South African high school was reported as $22 \% .{ }^{50}$

\section{CORRESPONDENCE:}

\author{
R M N Kohler \\ MRC/UCT Research Unit for Exercise Science and Sports \\ Medicine \\ Department of Human Biology \\ University of Cape Town \\ PO Box 115 \\ 7925
}

Tel: 021-659 5644

Fax: 021-659 5633

E-mail: ryank@yebo.co.za
In another study, the prevalence of concussion was reported as $50 \%$ in schoolboy rugby players, as the majority of mild head injuries are often not recognised and reported, at least in cases involving schoolboys ${ }^{59}$ (and Upton PA, Roux CE, Noakes TD - unpublished data). A similar prevalence has been noted in adult rugby players. ${ }^{56}$ In the 1999 Super 12 rugby competition, the incidence of concussion was reported as $20 \%$, the most common injury for that competition..$^{25}$

Traditionally, there has been a lack of universal agreement on a standard definition for concussion, making scientific research difficult. ${ }^{1}$ Furthermore, there is controversy regarding the ideal management of concussion in sport and a lack of objective data guiding return to play decisions." Sport organisations have relied on broad guidelines regarding head injury management and apply rigid, compulsory exclusion periods from sport depending on the injury grading and severity. Recently, significant advances and improvements in head injury management have been proposed at the First International Conference on Concussion in Sport, Vienna 2001.' During this conference, a comprehensive systematic approach to concussion was formulated for application in sport, which included computer-based neuropsychological testing as an integral part of concussion evaluation. ${ }^{+}$

\section{Pathophysiology}

The precise pathophysiology of concussion is unknown. Recently, research has shown that moderate to severe brain injury causes a complex cascade of neurochemical changes in the brain. The assumption is that similar changes occur in concussion. ${ }^{45}$ Injury to the brain cell membrane releases excitatory amino acids and induces ion flux, resulting in a decrease in blood glucose and oxidative metabolism and blood flow. ${ }^{26}$ This mismatch may account for the symptoms (Table I) ${ }^{1}$ and behavioural changes that are often associated with concussion. When the mismatch returns to normal, the symptoms usually disappear. The loss of consciousness that may occur with concussion is due to damage to the reticular activating system. The reticular activating system recovers relatively quickly and therefore consciousness is regained fairly soon after injury. ${ }^{52}$

\section{Severity of concussion}

The grading of the severity of concussion is controversial. ${ }^{46}$ At present there are at least 16 different classification systems for head injury severity. ${ }^{46}$ All, except the Glasgow Coma Scale designed for the assessment of severe head trauma, are based on anecdotal evidence and have not been scientifically validated. ${ }^{4.5,33,38,51.53,54,58,60,66}$ The two most commonly 


\author{
TABLE I. Symptoms and signs of concussion \\ Typical symptoms \\ Headache \\ Dizziness \\ Nausea \\ Unsteadiness/loss of balance \\ Confusion \\ Unaware of period, oppostion, score of game \\ Feeling 'dinged', stunned or 'dazed' \\ Seeing stars or flashing lights \\ Ringing in the ears \\ Double vision \\ Physical signs \\ Loss of consciousness/impaired conscious state \\ Poor co-ordination or balance \\ Concussive convulsion/impact seizure \\ Gait unsteadiness/loss of balance \\ Slow to answer questions or follow directions \\ Easily distracted, poor concentration \\ Displaying unusual or inappropriate emotions \\ Nausea/vomiting \\ Vacant stare/glassy eyed \\ Slurred speech \\ Personality changes \\ Inappropriate playing behaviour \\ Significantly decreased playing ability
}

used grading systems in sport are the Cantu and Colorado guidelines (Table II). ${ }^{4,16}$ However, there are a number of practical difficulties with concussion scales. Firstly, it may be impossible to be certain that loss of consciousness has occurred as it may be momentary and by the time the medical attendant reaches the player, the player may appear only dazed. ${ }^{46}$ There may also be inconsistencies between these scales in terms of return to play guidelines. A first time concussion associated with a loss of consciousness for less than 5 minutes correlates with a Cantu grade 2 injury and results in the player missing 1 week of play. The same injury correlates with a Colorado grade 3 injury and the player is rested for a minimum of 1 month. ${ }^{16}$ This may result in coaches and team physicians utilising the injury scale that suits their needs but which may not be the best medical manage-

TABLE II. The severity of concussion classification and return to play recommendations $s^{4,16}$

\begin{tabular}{|c|c|c|c|}
\hline Grade & $\begin{array}{l}\text { Return to play } \\
\text { recommendation }\end{array}$ & Cantu guidelines & $\begin{array}{l}\text { Colorado } \\
\text { guidelines }\end{array}$ \\
\hline $\begin{array}{l}\text { Grade } 1 \\
\text { (mild) }\end{array}$ & $\begin{array}{l}\text { May return to play } \\
\text { when } \\
\text { asymptomatic }\end{array}$ & $\begin{array}{l}\text { No LOC } \\
\text { PTA }<30 \text { min }\end{array}$ & $\begin{array}{l}\text { Confusion, } \\
\text { no amnesia } \\
\text { No LOC }\end{array}$ \\
\hline $\begin{array}{l}\text { Grade } 2 \\
\text { (moderate) }\end{array}$ & $\begin{array}{l}\text { Return if } \\
\text { asymptomatic } \\
\text { for } 1 \text { week }\end{array}$ & $\begin{array}{l}\angle O C<5 \mathrm{~min} \\
P T A>30 \mathrm{~min}\end{array}$ & $\begin{array}{l}\text { Confusion with } \\
\text { amnesia } \\
\text { No LOC }\end{array}$ \\
\hline $\begin{array}{l}\text { Grade } 3 \\
\text { (severe) }\end{array}$ & $\begin{array}{l}\text { May return after } \\
1 \text { monith if } \\
\text { asymptomatic } \\
\text { for } 2 \text { weeks }\end{array}$ & $\begin{array}{l}\angle O C>5 \mathrm{~min} \\
\text { PTA }>24 \text { hours }\end{array}$ & LOC \\
\hline
\end{tabular}

ment for the player. Also, cognitive (thinking) impairment may be as severe in an athlete who has lost consciousness as in an athlete who has not. ${ }^{34}$ Therefore, basing return to play decisions on the presence of loss of consciousness is inaccurate. Lastly, post-traumatic amnesia can only be determined in retrospect and is of little use for the on-field evaluation. ${ }^{46}$ The current grading scales attempt to be allinclusive, however this is not practically possible. ${ }^{46}$ As the above concussion classification systems lack scientific validity, then logically it is not accurate to base return to play decisions on these injury severity gradings. Objective measures for the return to sport following concussion are needed. ${ }^{1}$ The concept of traditional mandatory exclusion periods based on the above injury gradings are not helpful and are based on data from motor vehicle accidents. ${ }^{20.24}$

\section{Complications of concussion}

\section{Early}

Intracranial space occupying lesions. Concussion may be associated with damage to cerebral arteries and veins. Bleeding from these vessels may lead to epidural, subdural and intracerebral haematomas respectively. ${ }^{52,62}$ Signs of raised intracranial pressure have to be recognised immediately and treated surgically to decompress the brain.

Second impact syndrome. Diffuse cerebral swelling is a rare but well recognised complication of minor head injury and occurs mainly in children and teenagers. ${ }^{2,3}$ Second impact syndrome was first reported to occur in American football players who died after relatively minor head injury. ${ }^{6,61}$ This injury may occur if a player returns to play prematurely following a previous head injury. Brain swelling may still be present from the previous injury. ${ }^{46}$ A second blow results in further swelling, followed by loss of the brain's ability to control blood inflow (autoregulation). ${ }^{6}$ Cerebral blood flow increases rapidly and brain pressure rises uncontrollably leading to cardiorespiratory failure and death. ${ }^{6}$

Impact convulsions. Convulsions (seizures) in collision sports are not uncommon, but can appear as a dramatic event. ${ }^{46}$ They characteristically occur within 2 seconds of impact, but are not associated with structural brain damage. ${ }^{47}$ The good outcome with these episodes and the absence of long-term cognitive damage reflect the benign nature of these episodes, not warranting anti-epileptic treatment and preclusion from contact sports. ${ }^{47}$

\section{Late}

The possibility exists that repetitive minor head injury may cause chronic brain injury. Certainly there is growing concern that each episode of concussion may result in residual brain damage. ${ }^{21,22.57}$ This is most evident in the development of cognitive dysfunction in boxing, the degree of which is directly related to the number of bouts in a boxer's career. ${ }^{28.29}$ Cognitive deficits have also been documented in amateur, professional and retired soccer players, ${ }^{40.41 .64 .65}$ the hypothesis being that this is caused by frequently heading the ball. Genetic factors, associated with the ApoEe4 gene, may also increase the risk of developing chronic brain injury in sport. ${ }^{30-32}$ Future research will need to establish what severity of head injury causes summation and how long that residual effect 
may last.' Thus, it would be responsible to want to document a player's cognitive function periodically and note whether any cognitive deficit is present.

\section{Prevention of concussion}

The use of protective equipment has been advocated to reduce the risk of concussion in rugby. However, the evidence for the effectiveness of headgear and mouthguards to reduce the incidence and severity of concussion in rugby is inconclusive. $44.48,49$ Interestingly, rugby players believed that wearing headgear did prevent concussion, yet very few reported wearing headgear. ${ }^{55}$ The use of headgear in rugby serves to reduce the number of scalp lacerations and the use of mouthguards offers protection against dental injuries. ${ }^{17}$ It has been suggested that strengthening and conditioning of the neck muscles together with rule changes may also reduce the incidence of concussion. ${ }^{5}$

\section{Risk of a second concussion}

Players with a past history of concussion may be at increased risk of subsequent concussion. ${ }^{19}$ This however remains controversial and it seems that certain players display a high risk playing technique (tackling head on) that places them at increased risk of concussion. The risk of concussion is a feature of any collision sport and is directly related to the amount of time spent actually playing the sport. Therefore, the chance of repeat concussion may reflect the level of exposure to injury risk. ${ }^{52}$

\section{Clinical approach to head injury manage- ment}

\section{Immediate}

The aim of immediate management is to stabilise the headinjured player. Basic aspects of first aid involving cervical spine protection followed by airway, breathing and circulation evaluation take priority. ${ }^{46}$ Following this assessment, the team physician should decide whether the injured player is able to continue playing or is concussed and not fit to continue the game. At the field a simple neuropsychological test can be administered. Maddocks's questions assess recent memory and are sensitive in discriminating between concussed and non-concussed players (Table III). ${ }^{36,67}$ The standard approach of asking orientation item questions (time, place and person) has been shown to be unreliable, as this component of cognitive function may be preserved in concussion. ${ }^{36,43}$ Other simple tests such as three-item recall or digit span to determine whether post-traumatic amnesia has resolved could be used. ${ }^{63}$ It should be emphasised that the concussed player must be medically assessed as soon as possible following injury. ${ }^{46}$ it is not within the expertise of a physiotherapist, fitness trainer or non-medical person to manage concussion injury.

\section{Early}

The main aim of this assessment is to determine if there are urgent indications for referral to hospital (Table IV). ${ }^{46}$ Best performed in a quiet medical room, this assessment involves

\section{TABLE III Maddocks's questions ${ }^{35}$}

Which ground are we at?

Which team are we playing today?

Who is your opponent at present?

Which quarter is it?

How far into the quarfer is it?

Which side scored the last goal?

Which tean did we play last week?

Did we win last week?

a thorough history and neurological examination, noting any symptoms of concussion and excluding potential catastrophic signs of intracranial injury. Following this, the team physician must decide if there is any indication to perform neuroimaging special investigations. If the player has been unconscious for any period of time, it is recommended that either a computed tomographic or magnetic resonance image scan be performed. ${ }^{46}$ If there are no indications for these investigations and the concussed player is discharged home, he/she should be in the care of a responsible adult who is in possession of a head injury evaluation form. ${ }^{46}$

\section{Late}

The aim is to determine whether the player has fully recovered from concussion and is able to return to play. ${ }^{46}$ This is best performed by combining a clinical assessment with neuropsychological testing as an objective and scientifically valid means of assessing recovery. This is essential as post-concussion recovery rates vary between individuals. . $^{23.35}$ Some players may take days and others may take weeks to recover. Individual factors associated with each concussion injury are different and emerging evidence has hinted that genetic factors may be involved in both the response to head injury and recovery rates. ${ }^{1,30-32}$ There are dangers associated with universal mandatory exclusion criteria. It may be tempting to assume that a player has completely recovered from concussion as soon as the arbitrary time period has passed and

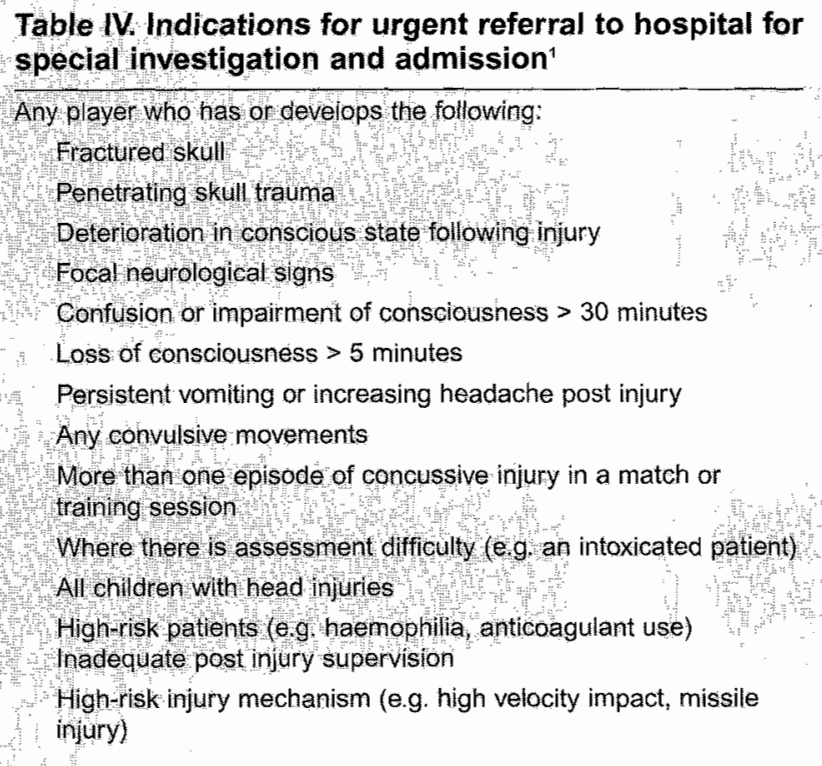


that a medical assessment is not necessary, when in fact brain function is still abnormal. ${ }^{4 \hat{6}}$

\section{Neuropsychological testing}

A neuropsychological test is designed to assess the ability of the brain to process information (cognitive function). ${ }^{37}$ Traditional 'paper and pencil' tests, such as the Digit Symbol Substitution Test, have been replaced by computerised neuropsychological tests. ${ }^{8,9,37}$ Computer tests are quick and easy to administer, show minimal learning effects and more importantly, are able to detect very subtle changes in cognitive function by measuring response variability, a feature not found with the paper and pencil tests. ${ }^{13,14.18,37}$ Computerised tests are cost effective and easily accessible to a large number of players. ${ }^{7}$ A doctor can administer the test, as the aim of the test is to determine whether cognitive dysfunction is present and not the reason for abnormal function.? A neuropsychologist can be consulted if cognitive function is severe and prolonged. ${ }^{7}$ Examples of computerised tests include CogSport (CogState Ltd. Australia) and Impact (Impact Applications: University of Pittsburgh Medical Center). The South African Rugby Football Union utilises the CogSport neuropsychological test, developed by leading concussion neuroscientists in Australia and peer-reviewed in the medical literature, as an objective measure of cognitive function following head injury. ${ }^{10,12-15,39}$ This test is able to measure performance variability, a key measure in concussion diagnosis. ${ }^{37}$ The test can be administered by team physicians and performed as part of a pre-season evaluation forming a baseline neuropsychological assessment. The baseline test ensures reliable comparative data, will aid in the detection of subtle cognitive impairment, eliminates the need to compare with 'normative data' and assists with accurate clinical decision-making. The baseline data also ensure that baseline performance is not adversely affected by disease, drugs, practice effects and malingering. ${ }^{11,15,18,42}$ A report detailing the player's response speed, accuracy and consistency is generated. ${ }^{37}$ The test can be repeated following a head injury to determine whether cognitive function has deviated from baseline. ${ }^{8,37}$ The benefits are that the player returns to play fully recovered and has the ability to perform sports-specific skills optimally.

\section{Return to play protocol}

A structured and supervised concussion rehabilitation proto$\mathrm{col}$ is conducive to optimal injury recovery and safe return to play. ${ }^{1,27}$ Any return to play decision must be preceded by both clinical and cognitive recovery, simply because cognitive recovery often lags behind complete resolution of post-concussion symptoms. Following this, a graded rehabilitation programme is commenced. The end point is a return to match competition. Return to play following concussion follows a stepwise process:

1. No activity and complete rest until the player is asymptomatic.

2. Neuropsychological test parameters return to baseline pre-season values.

3. Exercise rehabilitation programme: (i) light aerobic exer- cise (walking and stationary cycling); (ii) sport specific training (running drills, ball handling skills); (iii) non-contact drills; (iv) full-contact practice; (v) game play.

The player can proceed in a stepwise progression to the level above provided he/she is asymptomatic. ${ }^{1}$ If any postconcussion symptoms develop, the player should drop back to the previous asymptomatic level. A minimum of 24 hours should elapse before progressing to the next step.

\section{Conclusion}

The ideal management of concussion in sport has been an enigma. The guidelines proposed by the world's leading concussion experts at the Vienna Conference and the South African Rugby Management Guidelines on Concussion, provide the team physician with a structured approach to concussion and the necessary tools to make sound judgment decisions regarding return to play. In professional sport team physicians are not immune to litigation and this approach may afford the necessary medicolegal protection.

\section{REFERENCES}

1. Aubry M, Cantu R, Dvorak J, et al. Summary and agreement statement of the First International Conference on Concussion in Sport, Vienna 2001. Recommendations for the improvement of safety and health of athletes who may suffer concussive injuries. Br J Sports Med 2002; 36: 6-10.

2. Bruce D. Delayed deterioration of consciousness after trivial head injury in childhood. BMJ 1984; 289: 715-6

3. Bruce D, Alavi A, Bilaniuk L, Dolinnskas C, Obrist W. Diffuse cerebral swelling following head injuries in children: the syndrome of "malignant brain oedema'. J Neurosurg 1981; 54: 170-8.

4. Cantu RC. Guidelines for return to contact sports after cerebral concussion. The Physician and Sportsmedicine 1986; 14: 75-83.

5. Cantu RC. Cerebral concussion in sport. Management and prevention. Sports Med 1992; 14: 64-74.

6. Cantu RC. Second-impact syndrome. Clin Sports Med 1998; 17: 37-44

7. Collie A, Maruff P. Should neuropsychological testing be performed by neuropsychologists or team doctors. Br J Sports Med 2002 (in press).

8. Collie A, Darby D, Maruff P. Computerized cognitive assessment of athletes with sports related head injury. Br J Sports Med 2001; 35: 297-302.

9. Collie A, Maruff P, Darby D. Computerized neuropsychological testing in sport. Br J Sports Med 2001; 35: 297-302.

10. Collie A, Maruff $P$, Darby $D$. The effects of practice on brief cognitive test battery administered four times in three hours. J Int Neuropsychol Soc 2002 (in press)

11. Collie A, Maruff $P$, Darby $D$. The effects of practice on cognitive test performance of neurologically normal individuals assessed at brief test-retest intervals. J Int Neuropsychol Soc 2002 (in press).

12. Collie A, Maruff P, Darby, D, McStephen M. A laboratory-based validation study of computerized cognitive screening tests in mild cognitive impairment. Br J Sports Med 2002 (in press).

13. Collie A, Maruff P, Makdissi M, McCrory P Darby D. CogSport: Reliability and correlation with conventional cognitive tests used in post-concussion medical examinations. Clin J Sport Med 2002 (in press).

14. Collie A, Maruff P, McCrory P, Darby D. Statistical procedures for determining the extent of cognitive change following concussion. $\mathrm{Br} J$ Sports Med 2002 (in press).

15. Collie A, Maruff P, McStephen M, Darby, D, Kolta M. Detecting feigned cognitive impairments with a computerized test battery: Comparison of seven proposed techniques for identifying malingering. Neuropsychology 2002 (in press).

16. Colorado Medical Society Sports Medicine Committee. Guidelines for the Medical Management of Concussion in Sports. Denver: Colorado Medical Society, 1991.

17. Cummins $N$, Spears |. The effect of mouthguard design on stresses in the tooth-bone complex. Med Sci Sports Exerc 2002; 34: 942-7.

18. Darby D, Maruff P, Collie A. Detection of mild cognitive impairment with multiple baseline assessments in one day. Neurology 2002 (in press). 
19. Gerberich SG, Priest JD, Boen JR, Straub CP, Maxwell RE. Concussion incidences and severity in secondary school varsity football players. $A m \mathrm{~J}$ Public Health 1983; 73: 1370-5.

20. Gronwall D. Performance changes during recovery after closed head injury. Proceedings of the Australian Association of Neurology 1976; 13: 143-7.

21. Gronwall $D$, Wrightson $P$. Delayed recovery of intellectual function after minor head injury. Lancet $1974 ; 2: 605-9$.

22. Gronwall D, Wrightson P. Cumulative effect of concussion. Lancet 1975; 2: 995-7.

23. Gronwall $D$, Wrightson $P$. Memory and information processing capacity after closed head injury. $J$ Neurol Neurosurg Psychiatry 1981; 44: 889-95.

24. Gronwall DM. Paced auditory serial-addition task: a measure of recovery from concussion. Percept Mot Skills 1977; 44: 367-73.

25. Holtzhausen L, Schwellnus M, Jakoet I, Pretorius A. Pre-season assessment of South African players in the 1999 rugby Super 12 competition. South African Journal of Sports Medicine 2002; 9: 15-21.

26. Hovda DA, Lee SM, Smith ML, et al. The neurochemical and metabolic cascade following brain injury: moving from animal models to man. J Neurotrauma 1995; 12: 903-6.

27. Johnston KM, McCrory P, Mohtadi NG, Meeuwisse W. Evidence-based review of sport-related concussion: clinical science. Ciin I Sport Med 2001; 11: 150-9.

28. Jordan B. Medical Aspects of Boxing. Boca Raton: CRC Press, 1993

29. Jordan BD. Sparing and cognitive function in professional boxers. The Physician and Sportsmedicine 1996; 24: 87-98.

30. Jordan BD. Apolipoprotein Ee4 and fatal cerebral amyloid angiopathy associated with demetia pugilistica. Ann Neurol 1997; 38: 698-9

31. Jordan BD. Genetic susceptibility to brain injury in sports: A role for genetic testing in athletes? The Physician and Sportsmedicine 1998; 26: 25-6.

32. Jordan BD, Relkin N, Ravdin L. Apolipoprotein E epsilon 4 associated with chronic traumatic brain injury in boxing. JAMA 1997; 278: 136-40.

33. Kelly JP Nichols JS, Filley CM, Lillehei KO, Rubinstein D, KleinschmidtDeMasters BK. Concussion in sports. Guidelines for the prevention of catastrophic outcome. JAMA 1991; 266: 2867-9.

34. Lenninger $B$, Grambling $S$, Farrell A, Kreutzer E, Peck E. Neuropsychological deficits in symptomatic minor head injury patients after concussion and mild concussion. J Neurol Neurosurg Psychiatry 1990; 53: 293-6.

35. Maddocks $D$, Dicker $G$. An objective measure of recovery from concussion in Australian rules footballers. Sport Health 1989; 7: 6-7

36. Maddocks DL, Dicker GD, Saling MM. The assessment of orientation following concussion in athletes. Clin J Sport Med 1995; 5: 32-5.

37. Makdissi M, Collie A, Maruff P, et al. Computerized cognitive assessment of concussed Australian Rules footballers. Br J Sports Med 2001; 35: 354 60 .

38. Maroon JC, Steele P, Berlin R. Football head and neck injuries - an update. Clin Neurosurg 1980; 27: 414-29.

39. Maruff P, Collie A, Darby D, Weaver-Cargin J, McStephen M. Poor declarative memory in mild cognitive impairment is not due to impairments in attention, response strategy or depressed mood. Developmental Neuropsychology 2002 (in press)

40. Matser EJ, Kessels AG, Lezak MD, Jordan BD, Troost J Neuropsychological impairment in amateur soccer players. JAMA 1999; 282: $971-3$

41. Matser JT, Kessels AG, Jordan BD, Lezak MD, Troost J. Chronic traumatic brain injury in professional soccer players. Neurology 1998; 51: 791-6.

42. McCrea M, Kelly JP, Kluge J, Ackley B, Randolph C. Standardized assessment of concussion in football players. Neurology 1997; 48: 586-8.

43. McCrea M, Kelly JP, Randolph C, Kluge J, Bartolic E, Finn G, Baxter B. Standardized assessment of concussion (SAC): on-site mental status evaluation of the athlete. J Head Trauma Rehabil 1998; 13: 27-35

44. McCrory P. Do mouthguards prevent concussion? Br J Sports Med 2001 35: 81-2.

45. McCrory P. Should we treat concussion pharmacologically? $\mathrm{Br} J$ Sports Med 2002; 36: 3-5.

46. McCrory PR. Were you knocked out? A team physician's approach to initial concussion management. Med Sci Sports Exerc 1997; 29: S207-S12.

47. McCrory PR, Bladin PF, Berkovic SF. Retrospective study of concussive convulsions in elite Australian rules and rugby league footballers: phenomenology, aetiology, and outcome. BMJ 1997; 314: 171-4.

48. Mcintosh AS, McCrory P. Impact energy attenuation performance of football headgear. Br J Sports Med 2000; 34: 337-41.

49. Mcintosh AS, McCrory P. Effectiveness of headgear in a pilot study of under 15 rugby union football. Br J Sports Med 2001: 35: 167-9.

50. Nathan $M$, Goedeke $R$, Noakes $T$. The incidence and nature of rugby injuries experienced at one school during the 1982 rugby season. South African Journal of Sports Medicine 1983; 64: 132-7

51. Nelson W, Jane JGJ. Minor head injury in sports: a new system of classification and management. The Physician and Sportsmedicine 1984; 12: 103-7.

52. Noakes $T$, Du Plessis $M$. Common rugby injuries, including anatomical sites and mechanisms of injury. In: Noakes T, du Plessis M, eds. Rugby Without Risk. Cape Town: J L van Schaik, 1996: 45-86

53. Ommaya AK. Biomechanical aspects of head injuries in sports. In: Jordan $B$, Tsaris $P$, Warren $R$, eds. Sports Neurology. New York: Aspen Publishers, 1990: 84-97.

54. Ommaya AK, Gennarell TA. Cerebral concussion and traumatic unconsciousness. Correlation of experimental and clinical observations of blunt head injuries. Brain 1974; 97: 633-54.

55. Pettersen JA. Does rugby headgear prevent concussion? Attitudes of Canadian players and coaches. Br J Sports Med 2002; 36: 19-22.

56. Petterson J, Skelton R. Glucose enhances long-term declarative memory in mildly head-injured varsity rugby players. Psychobiology 2000; 28: $81-9$

57. Rimel R, Girdani B, Barth J, Boll T, Jane J. Disability caused by minor head Injury. Neurosurgery 1981; 9: 221-8.

58. Roberts $W$. Who sits? Who plays? Managing concussion on the sidelines. The Physician and Sportsmedicine 1991; 20: 66-72

59. Roux C, Goedeke R, Visser G, Van Zyl W, Noakes T. The epidemiology of schoolboy rugby injuries. S Afr Med $J$ 1987; 71: 307-13.

60. Saal J. Common American football injuries. Sports Med 1991; 12: 132-47.

61. Saunders $\mathrm{R}$, Harbaugh $\mathrm{R}$. The second impact in catastrophic contactsports head trauma. JAMA 1984; 252: 538-9.

62. Schneider R, Reifel E, Crislor H, Osterbam B. Serious and fatal football injuries involving the head and spinal cord. JAMA 1961; 177: 106-10.

63. Shores A. Preliminary validation of a clinical scale for measuring the duration of post-traumatic amnesia. Med J Aust 1986; 144: 569-72.

64. Tysvaer AT, Storli OV. Soccer injuries to the brain. A neurologic and electroencephalographic study of active football players. Am J Sports Med 1989; 17: 573-8.

65. Tysvaer AT, Storli OV, Bachen NI. Soccer injuries to the brain. A neurologic and electroencephalographic study of former players. Acta Neurol Scand 1989; 80: 151-6.

66. Wilberger JE, Maroon JC. Head injuries in athletes. Clin Sports Med 2002; 8: $1-9$.

67. Yarnell PR, Lynch $S$. The 'ding': amnestic states in football trauma. Neurology 1973; 23: 196-7. 